
\title{
\& Research Square \\ Individuals with protein deficiency carry vesicles that contribute to liver disease
}

Nazli Khodayari

Regina Oshins

L. Shannon Holliday

Virginia Clark

Qiang Xiao

George Marek

Borna Mehrad

Mark Brantly

\section{Video Byte}

Keywords: Cell Communication and Signaling, alpha-1 antitrypsin, extracellular vesicles, cytokine, miRNA, liver fibrosis, alpha-1 antitrypsin deficiency, AATD, gain of function, inflammation, liver disease, mutation, cirrhosis, small RNA sequencing, hepatic stellate cells, HSCs, fibrogenesis, hepatic injury, pathological cargo, cell migration

Posted Date: November 12th, 2020

DOl: https://doi.org/10.21203/rs.3.rs-106672/v1

License: (9) This work is licensed under a Creative Commons Attribution 4.0 International License. Read Full License 


\section{Abstract}

Alpha-1 antitrypsin deficiency (AATD)-mediated liver disease is a form of toxic inflammation associated with the retention of mutant alpha- 1 antitrypsin within cells. Patients with this disease typically show fibrosis and cirrhosis of the liver. Unfortunately, the mechanism of AATD-mediated liver disease is not well understood. To gain some insight, researchers recently explored the role of extracellular vesicles in the progression of AATD-mediated liver disease. They isolated vesicles from the plasma of individuals with both AATD and liver disease and compared them with vesicles from healthy individuals in terms of cytokine and chemokine expression as well as miRNA expression. Vesicles from individuals with AATD were shown to activate hepatic stellate cells in vitro, which is believed to be one of the first steps of fibrosis. a process mediated by the NF-KB and JAK/STAT signaling pathways. The result was a model of how plasma-circulating extracellular vesicles modulate the immune response of the liver by activating hepatic stellate cells. Involving more patients in future studies could help expand these findings to other liver injuries. and could lead to new treatments or preventive strategies for AATD-mediated liver disease. 